\title{
Polish Model of Psychiatric Hospitalisation without a Patient's Consent
}

\section{Kmieciak B*}

Faculty of Medical Law, Medical University of Lodz, Poland

*Corresponding author: Blazej Kmieciak, Faculty of Medical Law, Medical University of Lodz, Tel: 6964488 80; Email: blazej.kmieciak@umed.lodz.pl

\section{Review Article}

Volume 3 Issue 1

Received Date: December 11, 2017

Published Date: January 03, 2018

\section{Abstract}

There is a renowned ethical and legal standard for medical activities oriented on a patient, what has been observed for several decades. According to such a standard, every diagnostic activity and treatment may take place explicitly with patients consent. In relation to this, the key importance of patient's autonomy and dignity is demonstrated. Historical data is recalled in such a context many times. A proportion of researchers recall the Second World War period, when German physicians made para-medical experiments on sick people. We may add that in such a period at least several dozen thousand patients from psychiatric hospitals were killed. Such activities majorly took place at territory of Poland and it had to strongly influence on specialists, who coped with mental health protection in the following years. Legal rules in such area were introduced at territory of Poland in the end of the 20th century. Psychiatrists have initiated such changes. Such changes particularly referred to the principles of activity without the patient's consent. Polish standards for the forced psychiatric hospitalisation, that were introduced nearly 30 years ago, will be presented in this paper. Nevertheless, they certainly have the representative character in the area of such solutions, as they are currently undertaken in other countries.

Keywords: Human rights; Protection of mental health; Human dignity; Scientific research; Mentally sick patient

\section{Introduction}

In the end of June, 2015, Committee of Bioethics of the European Council adopted Draft Explanatory Report to the Additional Protocol of the European Bioethical Convention. Such a Protocol concerned in its general part the matters of forced hospitalisation and forced treatment for people suffering from psychical disorders. The document generally concerned the most important issues related with the protection of human rights and freedom of a person referred to the hospital without consent. First, it was demonstrated that such activities should be of exceptional character. The sole existence of mental disorders cannot be taken for sufficient recommendation for the implemented forced activates. Second, it was recalled that when the activities of similar character are introduced, the criteria guaranteeing the respected patient's human rights must be simultaneously introduced.

Thus, it pertains to:

- Examination of a sick person by an expert (namely a psychiatrist).

- Supervision for similar activities by judicial or administrational institutions,

- Opportunity for efficient protection of people's rights who participate in such therapy.

It was simultaneously added, that the member states of the European Council can adopt other initiatives with 


\section{Psychology \& Psychological Research International Journal}

broader extent, oriented on the protection of patient's rights in the psychiatric hospital [1]. Such a conclusion redirects to the matters of the Polish Mental Health Protection Act [2]. The most modern history of Poland has involved the psychiatric cases many times. First, we should recall the Nazi T4 Action, that took place during the Second World War. As a result, Germans killed at least several dozen thousand mentally sick people. Such activities occurred in the hospitals that still operate at territory of Poland $[3,4]$. We should add that the detailed phenomenon has occurred in the concerned country. We should add that in several dozen years when Poland was governed by socialistic party, the psychiatry was used for political purposes, whereas such a phenomenon was exceptional in the history of the Soviet Union and countries under influence of the Union [5]. The Mental Health Protection Act adopted in Poland, 1994, is compliant with all standards stipulated in the Draft Additional Protocol of the European Council stipulated above. It particularly concerns the problems of forced hospitalisation and forced treatment for mentally sick people. Specification for the solutions adopted in the Act will be presented below, that may be certainly taken for guidelines for other legal acts of similar character.

\section{Consent - Lacking Consent}

In the beginning, when analysing the psychiatry, it is said that it should be described as one element in the broader medical reality. Standpoints suggesting that psychiatry is "another medical department" exist, what can be found many times. It is certainly a division of special character, requiring close insight and rationality in legal actions. In the Polish legal order, the principle of respecting the patient's autonomy covers all people treated in all types of hospital wards. Thus, when talking about people who may be treated in the psychiatric hospitals, we should say that the patient's consent for such a treatment is area of concern [6]. In the Mental Health Protection Act, what is particularly important, the "patient's consent" term was defined. It is understood as "a freely given consent of a person with mental disorders, who, irrespectively to the mental condition, is actually capable of understanding the information delivered in an accessible manner that concerns the purpose of admitting to the psychiatric hospital, the person's health state, proposed diagnostic and treatment activities, as well as foreseeable effects for such activities or ways for changing them" [7]. Thus, according to the Stanisław Dąbrowski's point of view, the sole existence of mental disorders in a patient is not sufficient for the conclusion that such a person is lacking of competences for giving consent. Whereas, the referred author reasonably stipulates, following many years of clinical expertise, that a group of patients exist who do not have critical attitude to own health state. Following similar cases, such people may undertake initiatives dangerous to themselves or other people. When such situation may result from the symptoms of mental disease, opportunity for forced activities towards such a patient exists [8]. When closer insight into such activities is being put aside, it should be emphasised that the Polish "Psychiatric Act" refers to the mixed model of forced activities. It is all about the combination of important legal and medical elements. On the one hand, the legislator has referenced to the fundamental standpoint, namely the principle of respecting human dignity that makes the key law. Such a principle can be observed in the introduction to the Act (in its Preamble), where it is stipulated that the mental health of human being is of special personal interest [9]. The Polish Civil Code enforces automatic protection for such rights [10]. On the other hand, a medical element is also demonstrated here. One factor is crucial, namely the forced treatment is only possible for people in particular clinical states [9].

The Polish Mental Health Protection Act allows for a treatment without consent explicitly in the case of mentally retarded or mentally sick people. The "disease" term demonstrated here is of special interest. In the Bioethics Committee of the European Council document, referred above, it was stipulated that the "mental disease" term is interpreted diversely in various countries [1]. When analysing such a concern, Stanisław Pużyński found that it does not exist in the international classification of diseases. About 20 years ago, the concern stipulated above was elaborated by Stanisław Dąbrowski. He added that the Polish Psychiatric Act, when enabling the forced medical activities, purposefully focuses on the people suffering from psychosis. He stated that only similar conditions may be dangerous for a patient with disabled: conscience, capability of critical thinking, capabilities of making rational decisions and satisfying basic life's requirements. In such a case, it all comes to doubtful patient's competences in the area of consent for a treatment [5].

\section{Forced Activities}

The Mental Health Protection Act foresees three treatment courses for patients without the granted consent. Each such mode foresees three types of supervision:

- Administrative: made by the head of ward or hospital director,

- Medical: made by a medical examiner or an admitting doctor, as well as a medical expert designated by the court. 


\section{Psychology \& Psychological Research International Journal}

- Legal-juridical: made by the guardian court and the Ombudsman for Psychiatric Hospital Patients [11].

The first course can be described as "immediate". It is stipulated in art. 23 of Act hereto. It is expected that a mentally sick person can be admitted to the psychiatric hospital without a consent (clinical aspect), who is simultaneously dangerous to oneself, or to life and health of other people (behavioural element). Such a person can be examined without consent, even before admitting to the hospital (art. 21 of the Act). In order to facilitate the admission stipulated above, a psychiatrist must examine such a person at territory of hospital: when conditions allow for this, such a decision should be consulted with other psychiatrist. Then hospital authorities are notified, whereas the information about the forced treatment is delivered to the Court generally within 48 hours. What is particularly important, a judge must come to the patient within three days for verification purposes, whether such a patient was admitted to the hospital according to law. Then an independent psychiatrist is designated, who must assess the situation from the medical point of view. After two weeks, a judge decides on future treatment, according to such grounds. In such a period, a patient can be diagnosed or treated [12].

Another requiring description course is psychiatric observation. It was constructed identically to the "immediate" course from the procedural point of view, with exception to the fact, that it can last only 10 days. In such a period, patient cannot take any medicines (art. 33, item 3 of the Act). The purpose of such course is explanation, whether the aggressive or self-endangering behaviour in a patient originates from the existence of mental disease (hallucination or delusions), or it comes from a mental disorder (neurosis, disorder of psychical development or personality disorders) [13].

The last course is described as a "conclusive". It pertains to the case, when a mentally sick person cannot basically satisfy own life's requirements. Simultaneously, the deteriorating health state can be observed. It is also assumed, that only hospitalisation can provide help for a patient. In this detailed case, a motion is filed to the court by relatives, what is required. A psychiatrist's report must be attached to the motion above, who sees the treatment in the psychiatric hospital as mandatory, in relation to the developing disease. When such a motion is received, the court designates an independent psychiatrist, who must assess the patient's condition. On such grounds, the court decides on future treatment [14].

\section{Conclusions}

The Polish psychiatric hospitalisation model directly and clearly refers to the human rights standards. It all comes to a person in a specific situation, who suffers from difficulties caused by a disease. It should be emphasised, that Polish psychiatrists have implemented activities oriented on the protection of patient's rights in the course of forced treatment at territory of hospital since many years. Following this, the precious and self-controlling pattern of a physician's activity originated in Poland [15]. Forced interventions are always a specific course. It is in breach to the patient's autonomy. According to Stanisław Dąbrowski, it is a paradox. A suffering human being may experience even greater difficulties, as a result of the applied force. Nevertheless, such a force is necessary for the protection of such a human being from own actions [5]. Such activity is many times described as "paternalism". Whereas, it is not oriented on making any harm to a sick person. Moreover, dominant role over a mentally sick person is not the goal of doctors and legislators [5]. We should say that many people suffer from disorders that limit or completely disable rational decisions. Such disorders sometimes provoke for dangerous decisions and activities. The force in similar cases is very often the personnel duty. Its application cannot be avoided in the responsible medicine. Whereas, the supervisory activities should be constantly applied in similar cases, what is hard for both patients and personnel. Only in such a manner the patient's dignity will be respected.

For this purpose, it is also necessary to take subjects such as: principles of treatment of patients with eating disorders: anorexia, bulimia, the introduction of procedures for treatment without consent, the current rules do not regulate this) rules for undertaking specific forced actions:

a. searching the patient,

b. picking up private items,

c. limiting contact with relatives (e.g. telephone contact)

d. principles of treating children in the psychiatric hospital:

e. introduction of procedures for informing young patients,

f. Treatment of people with behavioral disorders.

Constant discussion on these topics guarantees that there will be implemented priceless principle of medicine: first, does no harm. 


\section{Psychology \& Psychological Research International Journal}

\section{Acknowledgement}

The article was created as part of the implementation of the research topic "Legal and social challenges to mental health", financed with funds of the Medical University of Lodz - No. 502-03 / 6-074-06 / 502-64- 103.

\section{References}

1. Draft Explanatory Report to the Additional Protocol of the European Bioethical Convention, Strasburg 2015.

2. Act on August 19, 1994, on the Protection of Mental Health (Journal of Laws, No. 111, item 535, as amended).

3. Bomba J (2017) Modesty of Professor Wanda Półtawska, Psychiatrix for practitioners, 2: 70.

4. Katolo A (2012) Euthanasia and eugenics - Nazi experiences, Institute of Globalization, Gliwice.

5. Dąbrowski S (1995) The rights of the mentally ill and premises of forced hospitalization, in: Psychiatry and Ethic, (Ed.) Siwiak - Kobayashi M, Leder S, Library of Polish Psychiatry, Krakow, 53-60.

6. Pużyński S (2015) Dilemmas of contemporary psychiatry. Ethical, clinical and legal problems, Eneteia Publisher, Warsaw.

7. Gruszczyńska-Młodożeniec A, Pierzgalska K (2004) Selected legal issues in psychiatry. Interview with prof. S. Dąbrowski, Wiadomości Psychiatryczne 4: 293-297.

8. Kmieciak B (2017) Human rights of the mentally ill: dilemmas, questions and challenges: In Victims discriminated in scientific research and educational practice, interdisciplinary approach, (Ed.) Piotr Dzieduszycki, University of Business and Health Sciences, Lodz, 136-156.

9. Dąbrowski S, Pietrzykowski J (1997) Act on mental health protection - commentary, IPiN, Warsaw.

10. Karkowska D (2010) Psychiatric Patient's Rights, in: Mental Health Problems (Ed.) M Wojciechowska: AHE Publisher, Lodz, 143-157.

11. Gałecki P, Bobińska K, Eichstaedt K (2013) Law on mental health protection - commentary, LexisNexis, Warsaw.

12. Duda J (2006) Commentary on the Act on Mental Health Protection. Commentary, LexisNexis, Warsaw.

13. Kubiak R (2010) Medical Law, C.H.Beck Publishing House, Warsaw.

14. Kmieciak B (2015) Patients' rights and their protection. Sociological study, Scientific Publisher KUL.

15. Bomba J (1993) Humanistic Values, and Respect for Human Rights in Difficult Conditions. Psychiatr Pol 27(3): 225-238. 